\title{
Alternate Energy from Busy Road for Development of Smart City
}

\author{
Yogita D. Patil ${ }^{1}$, Dr. G S Mundada ${ }^{2}$ \\ AMIE Student, E\&TC, Pune, Maharashtra, India ${ }^{1}$ \\ Professor, E\&TC Department, PICT, Pune, Maharashtra, India ${ }^{2}$
}

\begin{abstract}
The world is facing energy crisis with the difference in demand and supply and limited number of natural resources. So there is a need for saving energy and requirement an alternate energy source which is cheap and feasible. This paper attempt to concentrate on how electrical energy can be generated from busy road using speed breaker, stored and used. In large metro cities the amount of vehicles increases gradually. Another way to generate the power by tapping this energy is possible by replacing normal speed breaker with this simple mechanism. The energy generated is stored for lighting street lights and for use in rural areas. Also energy saving is aim of this paper, using microcontroller and some electronic devices we on -off street light.
\end{abstract}

Keywords: Conversion, Busy Road, Speed Breaker, Energy.

\section{INTRODUCTION}

An energy crisis is any great bottleneck (or price rise) in the supply of energy resources to an economy. Energy crisis can develop due to Overconsumption, Overpopulation, Delay in Commissioning of Power Plants, Wastage of Energy. Sometimes bottlenecks at oil refineries and port facilities restrict fuel supply [1]. An energy crisis can arise due to over use of the resources and wastage of energy generated. This project addresses both the issues of energy saving as well as energy generation using simple mechanism of a speed breaker on a busy road. Energy changes from one form to the other". When a vehicle moves over the speed breaker there are lot of energies involved in the process. Energy due to friction, potential energy, heat etc. are lost in the environment. The idea is to utilize and convert the potential energy due to the weight of the vehicle to electrical energy. A mechanical shaft with the dynamo is used and placed on the plane of the road. When a vehicle passes on this roller, due to friction, the roller rotates which in turn moves shaft of the dynamo. When the shaft rotates it generates the voltage based on Faraday's law. This voltage can in turn be stored in a battery which can be further used to light the street bulbs. "A vehicle weighing $1,000 \mathrm{~kg}$ going up a height of $10 \mathrm{~cm}$ on such a rumble strip produces approximately 0.98 kilowatt power. So one such speedbreaker on a busy highway, where about 100 vehicles pass every minute, about one kilo watt of electricity can be produced every single minute. The figure will be huge at the end of the day," [2]

The second concept is "Energy Saving". Many times the street lights are kept ON in broad daylight or when there is no traffic on the road at midnight. Energy can be saved by switching ON the lights whenever and wherever necessary. Half of the lights can be switched OFF when there is no vehicle on the road and all can be switched OFF in broad daylight. LDR's are used to detect day and night and two infrared sensors are used at the two ends of the road to detect any activity the road. A microcontroller $89 \mathrm{C} 51$ is used as a control unit along with the sensors.

\section{SYSTEM IMPLEMENTATION}

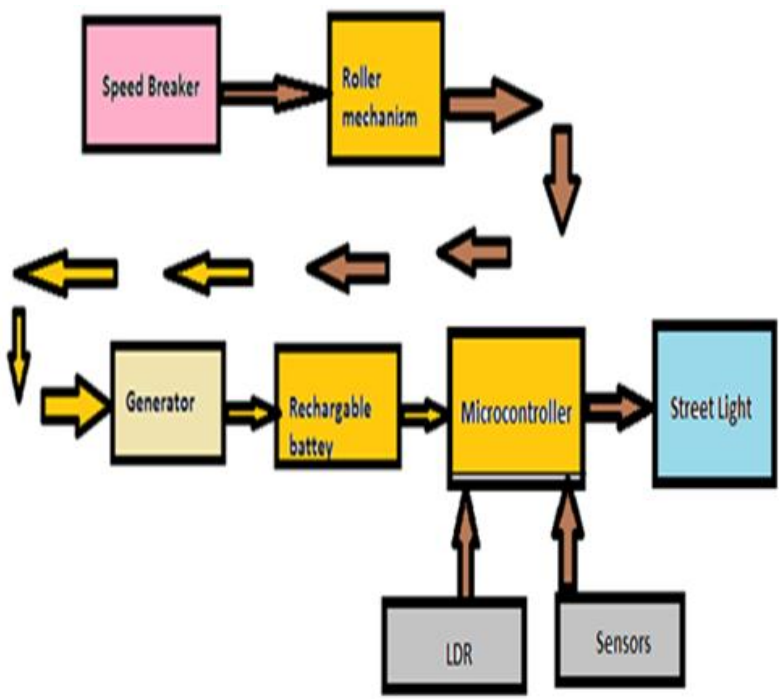

Fig.1 block Diagram of Energy Generation from Busy Road

Major Parts of the Systems:

a. Roller Mechanism

b. Generator

c. Microcontroller

d. LDR and Sensors

\section{a. Roller Mechanism}

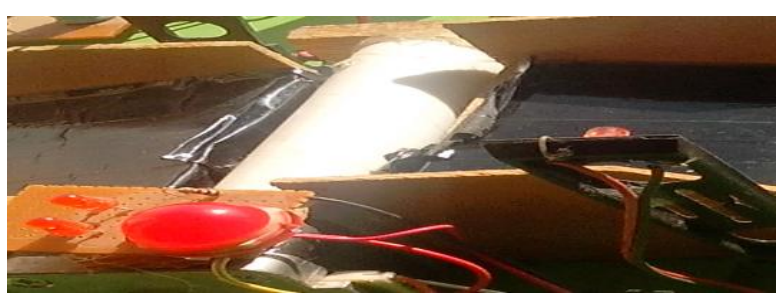

Fig. 2 Roller mechanism

In this set up, a roller is fixed on a wooden incline which works as a ramp. When vehicle is passes on the roller it 
rotates in the direction of the vehicle. The roller is coupled with the DC motor shaft which is used as a generator. Now, as the vehicle passes over it; the roller rotates the shaft of the DC motor which generates electricity. Hence DC power is generated by using the roller mechanism which can be stored in the battery and used for future. The advantage of this mechanism is that electricity can be proportionally generated without polluting the environment.

\section{b. Generator}

In this project dynamo works as generator.

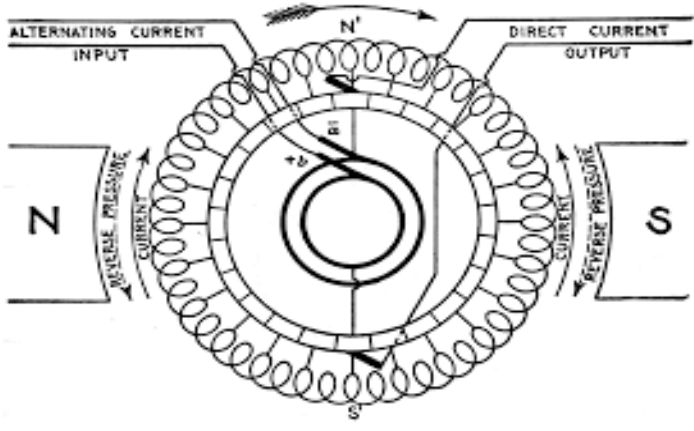

Fig.3 Dynamo

Dynamo works on the principle of Faraday's law to convert mechanical energy into electrical energy. It generates direct current. The shaft from the roller is connected to the generator to generate power. A dynamo consists of a stator, a fixed structure which generates magnetic field. The armature on the other hand consists of copper winding which rotates in the magnetic field created by the stator. For smaller machines permanent magnet can be used but for larger machines electromagnets are used.

In a direct current power is needed to flow in only one direction. The rotating armature in a dynamo reverses the current every half cycle. A commutator is employed as a rotary switch, which cuts off the power during the reverse current thus generating direct current power.

\section{Microcontroller}

In this project we use AT89C51 Microcontroller to control the light /bulbs with the help of sensors. The output of the sensor works as the input to the microcontroller. The LDR sensors are used to detect whether it's a day or night depending on which the lights are turned OFF or ON. The infra red sensor situated on the two ends of the road detects an activity on the road. If a vehicle is detected all the lights are turned $\mathrm{ON}$ otherwise only half of the lights are $\mathrm{ON}$ during night.

AT89C51 has 4KB of Flash programmable and erasable read only memory (PEROM). It can be erased and program to a max 1000 times

\section{LDR and Sensors}

LDR is device whose resistance varies with the amount of light falling of the surface. LDR is very sensitive to visible light. We use a comparator circuit to compare this voltage with the set reference voltage. In this circuit, when LDR is in light then there is less positive output on the comparator circuit. When LDR is in dark then the output of comparator becomes more positive. Microcontroller senses this voltage change and switches ON the LEDs which is connected to the port 2 through the current limiting resistors in series.

Sensors: In this part we use Infra-Red sensors.

\section{Infra-Red sensor: Detecting Brightness}

The sensor works on the principle of detecting the amount of reflected light. It has an emitter and detector assembly that works in infra-red spectrum. This assembly is used to detect a vehicle on the road. When light in infra-red spectrum is incident on the photodiode there is a proportional change in the resistance with the magnitude of reflected light.

When the vehicle enters a road it interrupts the first IR sensor, all LEDs on the street are turned ON. If there is no activity on the road, only half of the LEDs glow. Once the vehicle passes the other end it is detected by the other IR sensor thus turning OFF half of the LEDs if no other vehicle is present on the road. The comparator circuit compares the sensor output with the reference voltage.

\section{FLOW CHART}

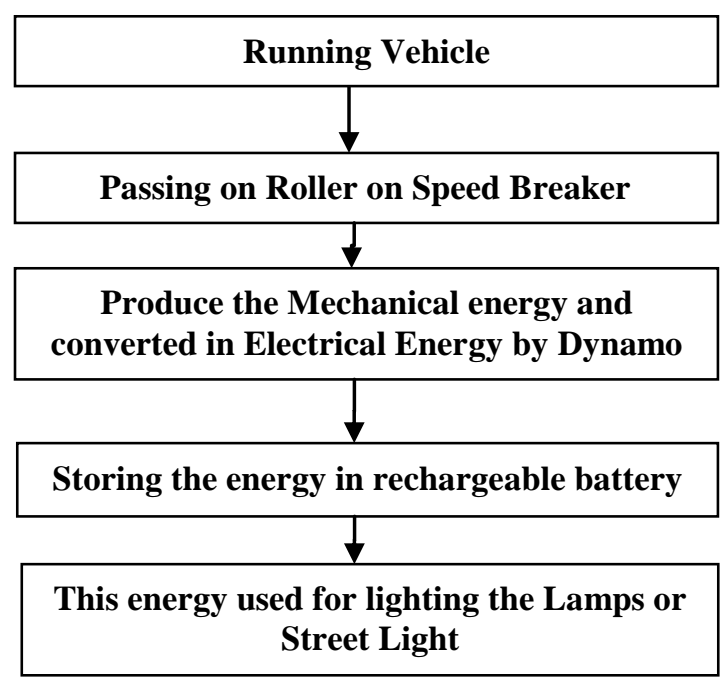

Fig.4 Flowchart of the system

\section{RESULT}

In this experiment Model, 9 volt Dynamo is present which give 7.2 volt dc output it is use for charge $5 \mathrm{v}$ to $6 \mathrm{v}$ battery. If we increase the range of dynamo we get more output. As per vehicle weight we have to decide the roller material for low maintenance cost.

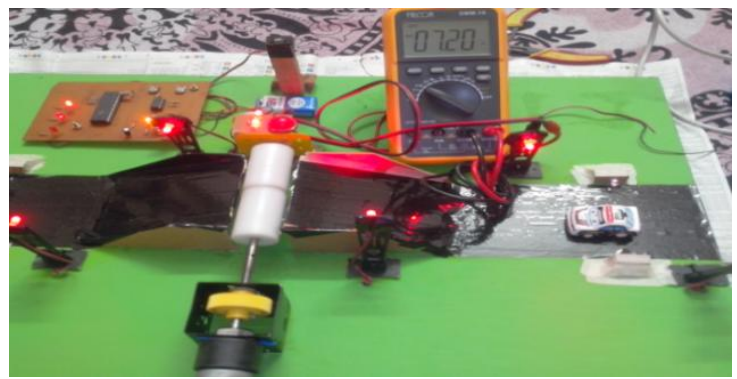

Fig. 5 Experiment Model of the System

\section{Power calculation}

The Velocity of moving vehicle is 5.4 Kilometre/hour 
INTERNATIONAL JOURNAL OF INNOVATIVE RESEARCH IN ELECTRICAL, ELECTRONICS, INSTRUMENTATION AND CONTROL ENGINEERING Vol. 4, Issue 2, February 2016

The weight of the load acting is $10 \mathrm{Kg}$.

Power $(\mathrm{P})=$ Work Done $(\mathrm{W}) /$ Time $(\mathrm{T})$

Force $=\mathrm{mg}=10 \times 9.81=98.1 \mathrm{~N}$

Distance $(\mathrm{s})=10$ Centimetre $=0.1 \mathrm{~m}$

Time $=$ Distance $(\mathrm{d}) /$ Speed $(\mathrm{s})$

Speed $=3.7 \mathrm{Km} / \mathrm{h}$

Time $(\mathrm{t})=1 \mathrm{sec}$

Power $=9.81 / 1=9.81$ watts

Power $=\mathrm{QV} / \mathrm{t}=\mathrm{IV}$

Where

$\mathrm{Q}=$ electric charge in coulombs

$\mathrm{t}=$ time in seconds

$\mathrm{I}=$ electric current in amperes

$\mathrm{V}=$ electric potential or voltage in volts

Voltage Generated $=2 \mathrm{v}$

Current generated $=2$ amps

Electric Power $=2 \times 2=4$ watts

For $10 \mathrm{~kg}$ weight vehicle speed is $3.7 \mathrm{~km} / \mathrm{h}$ we get 4

Watt power. As vehicles passes on it we will get more

Power which we use to charge the battery

From that calculation we get this table.

\begin{tabular}{|l|l|l|}
\hline Sr. No & Load (Kg) & Power Generated (Watts) \\
\hline 1 & 10 & 9.81 \\
\hline 2 & 20 & 19 \\
\hline 3 & 30 & 24 \\
\hline 4 & 40 & 28 \\
\hline
\end{tabular}

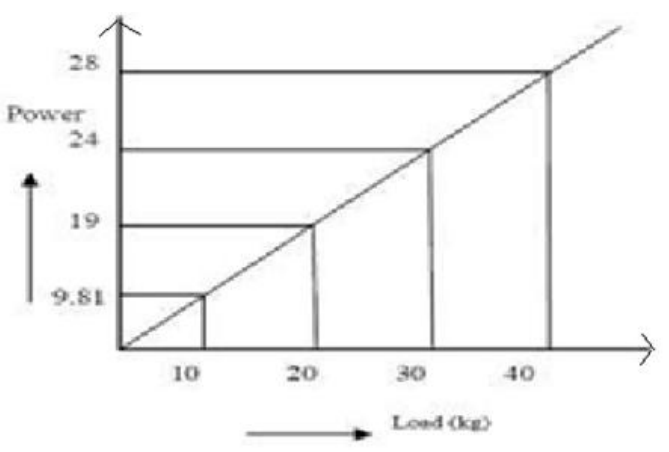

Circuit Diagram

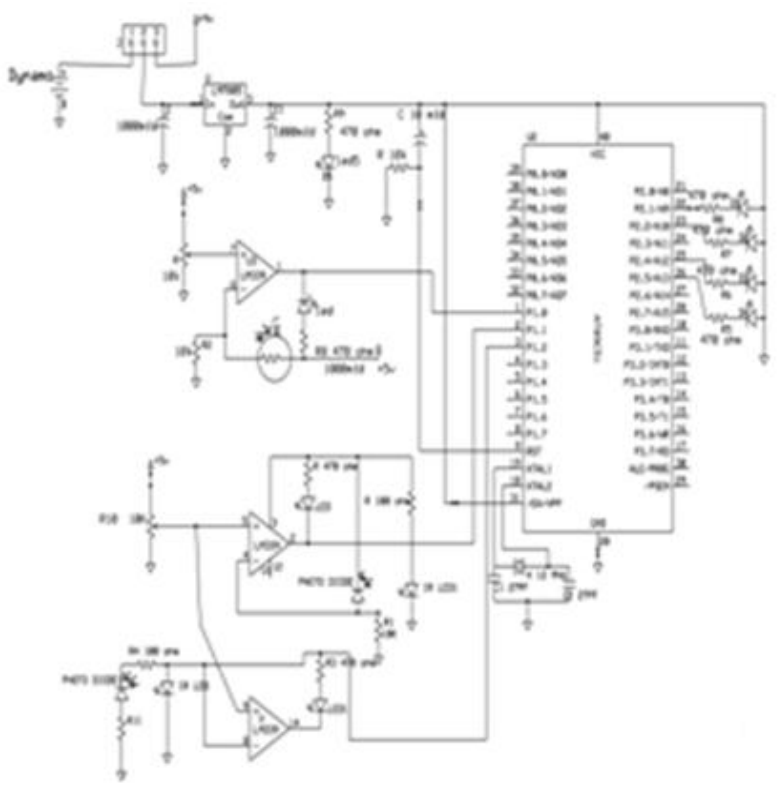

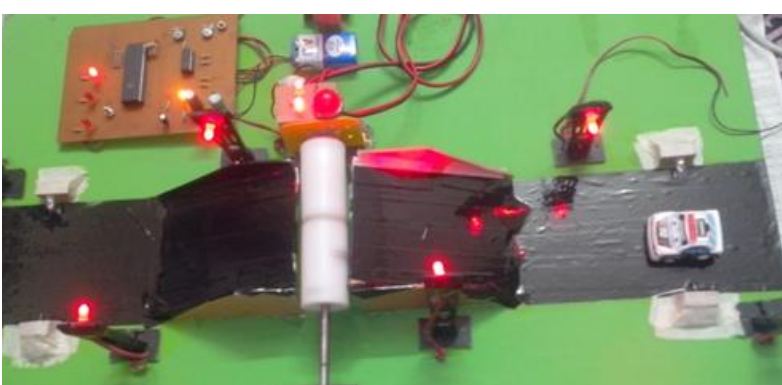

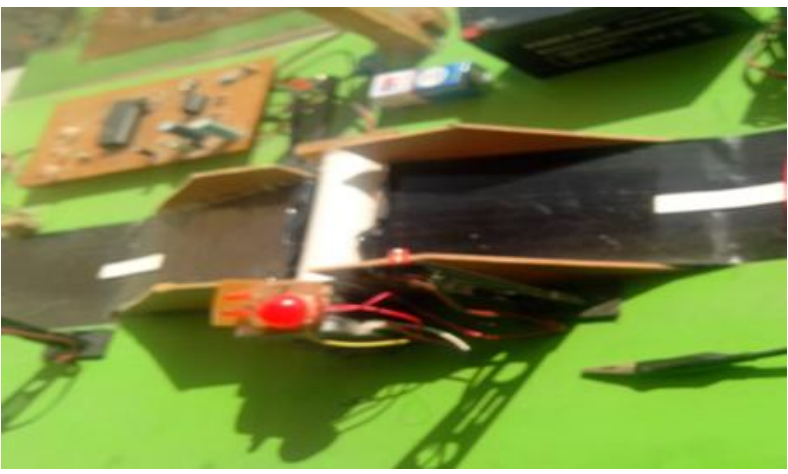

V. CONCLUSION

- The rollers used in this project can be intended/ upgraded for heavy vehicles Large amount of potential energy generated on the busy road can be converted into electrical energy which can be utilized to light the street lights

- This alternative source of energy can be used to provide an aid to the conventional energy sources thus improving the economy of the smart metro cities.

- "Energy saved is energy generated". This project also saves the power by utilizing it optimally during night and only if there is any activity on the road.

- Advantage of this system is it has not utilise any external source. Now the time has come to put forward this type of new ideas, and also researches should think to upgrade its proposal.

\section{FUTURE SCOPE}

- The rollers used in this project can beintended/ upgraded for heavy vehicles, thus increasing the input torque and eventually output of generator can also be increased. Output can be further increased by using of multiple transmission system.

- In future, if the flywheel speed control device and voltage protection devices can be added with large generation process, it would be a model all over the world.

- After some regulation of the intended project, the power generation of the system can be increased by increasing the capacity of the generator and applying more weight.

\section{REFERENCES}

[1] Ch.Bhanu Prakash1, A.V.Ramana Rao2, P.Srinuva, "Road Power Generation by Speed Breaker", International Journal of Engineering Trends and Technology (IJETT), and ISSN: 2231-5381, Volume 11 Number 2, pp. 75-78, May 2014.

[2] www.projectsworlds.blogspot.com 
[3] Kausal Pratap singh, Priyank Singh, ''Eco-Friendly Electricity Generator From Busy Road', International Journal of Emerging Trends in Engineering and Development(IJETED), ISSN 22496149, Issue 4, Vol.3, pp. 65-73, May 2014.

[4] Akshay Tank, Prof. Chandni V. Shah, Keyur Shah, "Eco-Friendly Energy Generation through Speed Breaker", International Journal of Engineering Development and Research (IJERD), ISSN: 23219939, Issue 1, Volume 2, pp. 1232-1235, 2014.

[5] "The 8051 Microcontroller and Embedded Systems" by Muhammad Ali Mazidi and Janice GillispieMazidi, Pearson Education.

[6] "8051 Microcontroller Architecture, programming and application by KENNETH J AYALA.

[7] ATMEL 89C51 Data sheet.

\section{BIOGRAPHIES}

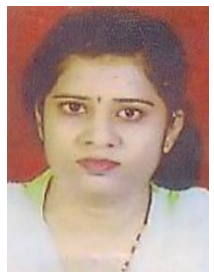

Ms. Yogita D. Patil is currently Pursuing AMIE (Institution of Engineers India) in Electronics and Telecommunication Engineering, Pune.

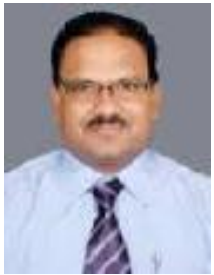

Dr. G. S. Mundada is Professor (ECE) and Head T\&P Cell at PICT, Pune. He is having teaching experience Of 20 years; research of 5 years and the area of interest include Power Electronics, Wireless Networks, Application of Devices and Circuits. He is recipient of Best Teacher Award of Savitribai Phule Pune University during 2014-15. 